\title{
A Granger causality test of the causal relationship between the number of editorial board members and the scientific output of universities in the field of chemistry
}

\author{
Xing Wang
}

Editorial board members, who are considered the gatekeepers of scientific journals, play an important role in academia. The aim of this study is to explore the causal relationship between the number of editorial board members and the scientific output of universities. In this article, we have used time-series data and Granger causality test to explore the causal relationship between the number of editorial board members and the number of articles published by top universities in the field of chemistry. Furthermore, we interviewed some editorial board members about this causal relationship. The Granger causality test results suggest that the causal relationship is not obvious overall. Combining these findings with the results of qualitative interviews with editorial board members, we discuss the causal relationship between the two variables.

Keywords: Causality test, chemistry, editorial board members, scientometrics, scientific output of universities.

IN academia, the editorial boards of scholarly journals have an important influence on the quality and relevance of published research ${ }^{1}$. 'It is considered that the critical mentality and decisions of editorial boards protect the social and intellectual integrity of science. ${ }^{2}$ Editorial boards are important to the entire academic world, and there seems to be a possible relationship between the number of editorial board members and the scientific output of universities ${ }^{2-5}$. Several studies have examined the correlation between the two variables in some subjects. While some studies found a positive correlation between university ranking based on the number of editorial board members and scientific output ${ }^{6-11}$, others did not $^{12-14}$.

However, statistical correlation cannot be used as an indication of a causal relationship. Though editorial board members may be important to universities and there may be some relationship between the number of editorial board members and the scientific output of universities, there has been a lack of studies about the causality in this relationship. We know little about the direction of causality; that is, whether the number of editorial board members drives the scientific output, or vice versa. It may be more interesting to determine whether such a causal rela-

Xing Wang is in the School of Information Management, Shanxi University of Finance and Economics, Shanxi, China and Graduate School of Education, Shanghai Jiao Tong University, Shanghai, China. e-mail: wangxing830914@gmail.com tionship exists and, if so, which variable drives the other. Unfortunately, this important issue has been ignored in previous studies.

What is the mechanism of the relationship between the two variables? Could there be a causal relation? We suppose that there may be a interplay mechanism between the two variables.

On the one hand, in theory, editorial board members obtained their positions because of their high research achievements. In other words, only individuals with a strong record of published articles and citations are qualified as candidates for editorial boards. Extending this theory to the university level, the greater the quantity and impact of research produced by a university, greater is the probability that the university has a higher number of editorial board members.

There are two possible reasons for the influence of the number of editorial board members at a university on its scientific output. First, editorial board members may produce a substantial amount of high-impact scientific output for their universities owing to their outstanding research capabilities. Second, editorial board members, considered the gatekeepers of scholarly journals, may have influence on the scientific output of their universities by controlling the academic discourse (e.g. controlling the research hotspots of their respective fields and the themes of journal articles, making decisions to publish journal articles, and setting the academic evaluation

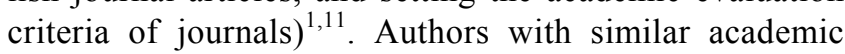


backgrounds to these editorial board members (e.g. working in or graduated from the same institution) might share similar academic viewpoints, research topics or research directions. Further, they might have similar preferences in research methods or paradigms. Owing to this conformity, authors from the same institutions as editorial board members might acquire academic recognition more easily, and, therefore, their articles are more likely to be published.

In this study, we used time-series data and Granger causality test to explore the potential causal relationship between the number of editorial board members and the number of articles published by the top 20 universities. We also interviewed some editorial board members about this causal relationship. We chose to focus on chemistry because the available data about the number of editorial board members in chemistry are relatively complete.

\section{Data and methodology}

\section{Samples for Granger causality test}

We collected time-series data for the Granger causality test using two variables: the number of editorial board members and the number of articles published per university. According to studies conducted by Brown ${ }^{15}$, we selected the following nine top journals as samples for the analysis: Journal of the American Chemical Society, Angewandte Chemie International Edition, Chemical Reviews, Accounts of Chemical Research, Analytical Chemistry, Biochemistry, Chemistry of Materials, Inorganic Chemistry and Journal of Organic Chemistry. Since majority of these journals did not reveal the affiliations of their editorial board members until 1998, we chose the period from 1998 to 2017.

We faced the risk that there might be a limited number of editorial board members from each university every year for these nine journals; so we used the top 20 universities (their number of editorial board members was higher every year) in chemistry according to Shanghai Ranking as our sample for the Granger causality test. We manually recorded and calculated the number of editorial board members from these 20 universities during 1998 to 2017 using the nine journals.

Employing the advanced search function of Clarivate Analytics' Web of Science, we obtained the number of articles published in the nine journals each year from 1998 to 2017 at the 20 universities. Data for both the number of editorial board members and the number of articles published were collected in June 2018.

\section{Granger causality test models}

The basic principle of the Granger causality test is as follows: To examine whether a variable $X$ is the cause of another variable $Y$, a restricted regression model represented by eq. (1) below should be established first to show that $Y$ can be explained by its own past values. Then, past values of $X$ as the explanatory variable are introduced into the eq. (1) to obtain an unrestricted regression model, yielding eq. (2). If introducing past values of $X$ can significantly improve the prediction level of $Y$, then $X$ is said to be the Granger cause of $Y$. Similarly, these steps can be repeated to determine whether $Y$ causes $X$.

$$
\begin{aligned}
& Y_{t}=\alpha_{0}+\sum_{i=1}^{m} \alpha_{i} Y_{t-i}+\mu_{t}, \\
& Y_{t}=\alpha_{0}+\sum_{i=1}^{m} \alpha_{i} Y_{t-i}+\sum_{j=1}^{m} \beta_{j} X_{t-j}+\mu_{t},
\end{aligned}
$$

where $X$ represents the number of editorial board members, $Y$ the number of articles published. $\alpha_{0}$ the constant, $\mu_{t}$ the white noise sequence, $\alpha_{i}$ and $\beta_{j}$ are coefficients, and $m$ is the number of lagged terms. For both eqs (1) and (2), the longer the lag length, better will it reveal the dynamic features of the models. However, if the lag length is too long, the freedom of the model will be reduced. Thus, there needs to be a balance between the two variables. Moreover, from the perspective of actual publishing cycles, the publishing cycle of articles from the American Chemical Society is $4-8$ months; from the perspective of editorial board members as a research manpower input, some scholars choose a lag of 1-3 years $^{16,17}$. However, from the perspective of the period when the editorial board members obtained their positions, there is no fixed standard. Based on the above factors and for the sake of prudence, we selected a lag length of 1-5 years for this test.

\section{Samples for e-mail interview}

To deepen our understanding of the relationship between the number of editorial board members and the scientific output, we conducted semi-structured interviews with several board members from the nine journals. Considering that most of the board members resided outside of China, interviews were conducted via e-mail. In total, 130 e-mails were sent and 16 board members answered our interview questions.

\section{Results and discussion}

\section{Analysis of Granger causality test}

The prerequisite of the Granger causality test is that the two series are stationary or co-integrated; otherwise the problem of 'spurious regression' might occur. Therefore, 
GENERAL ARTICLES

Table 1. Granger causality test between the number of editorial board members and the number of articles of universities (1998-2017)

\begin{tabular}{|c|c|c|c|c|c|c|c|}
\hline Rank & University & EB & PUB & Co-integration & $\mathrm{EB} \rightarrow \mathrm{PUB}$ & $\mathrm{PUB} \rightarrow \mathrm{EB}$ & Lag \\
\hline 1 & UC-Berkeley & $I(0)$ & $I(1)$ & & - & - & - \\
\hline 2 & Harvard University & $I(0)$ & $I(1)$ & & - & - & - \\
\hline \multirow[t]{5}{*}{3} & Stanford University & $I(1)$ & $I(1)$ & $\sqrt{ }$ & $7.354 * *(0.015)$ & $0.026(0.875)$ & 1 \\
\hline & & & & & $3.571 *(0.058)$ & $0.543(0.593)$ & 2 \\
\hline & & & & & $4.066 * *(0.040)$ & $0.627(0.614)$ & 3 \\
\hline & & & & & $4.342 * *(0.044)$ & $0.217(0.921)$ & 4 \\
\hline & & & & & $6.858 * *(0.043)$ & $1.119(0.470)$ & 5 \\
\hline 4 & Northwestern University & $I(1)$ & $I(0)$ & & - & - & - \\
\hline 5 & University of Cambridge & $I(0)$ & $I(1)$ & & - & - & - \\
\hline 6 & MIT & $I(0)$ & $I(1)$ & & - & - & - \\
\hline 7 & CalTech & $I(0)$ & $I(1)$ & & - & - & - \\
\hline 8 & ETH-Zurich & $I(1)$ & $I(0)$ & & - & - & - \\
\hline 9 & Kyoto University & $I(1)$ & $I(1)$ & $\sqrt{ }$ & $1.705(0.229)$ & $1.227(0.350)$ & 3 \\
\hline \multirow[t]{3}{*}{10} & UCLA & $I(0)$ & $I(0)$ & & $5.806 * *(0.028)$ & $1.870(0.190)$ & 1 \\
\hline & & & & & $5.944 * *(0.015)$ & $1.679(0.225)$ & 2 \\
\hline & & & & & $2.879 *(0.089)$ & $0.873(0.487)$ & 3 \\
\hline 11 & University of Pennsylvania & $I(0)$ & $I(1)$ & & - & - & - \\
\hline 12 & Yale University & $I(1)$ & $I(1)$ & & - & - & - \\
\hline 13 & UC-Santa Barbara & $I(0)$ & $I(1)$ & & - & - & - \\
\hline 14 & University of Oxford & $I(0)$ & $I(1)$ & & - & - & - \\
\hline 15 & Columbia University & $I(1)$ & $I(0)$ & & - & - & - \\
\hline 16 & Tech University Munich & $I(1)$ & $I(1)$ & & - & - & - \\
\hline 17 & University of Strasbourg & $I(0)$ & $I(0)$ & & $2.329(0.217)$ & $54.730 * * *(0.001)$ & 5 \\
\hline 18 & Rice University & $I(0)$ & $I(1)$ & & - & - & - \\
\hline 19 & UC-San Diego & $I(0)$ & $I(1)$ & & - & - & - \\
\hline 20 & University of Tokyo & $I(0)$ & $I(0)$ & & $3.797(0.110)$ & $0.469(0.786)$ & 5 \\
\hline
\end{tabular}

EB and PUB represent respectively the number of editorial board members and the number of articles published.

Column 1 shows the 2014 Shanghai ranking of the selected universities in chemistry.

Columns 3 and 4 show the data characteristics of the EB and PUB series respectively. If the series itself is stationary, we represent it by $I$ ( 0 ). If the series is integrated with order $n$, we represent it by $I(n)$. Column 5 uses ' $\sqrt{ }$ ' to indicate that the two series were co-integrated.

Columns 6 and 7 represent the $F$-value of the Granger causality test. $P$-value in parentheses: ***, ** and * significant at $1 \%$, $5 \%$ and $10 \%$ significant level respectively.

Column 8 shows the lag phase. For the three universities that had a significant causal relationship between the two variables, the lag phases having significant causal relationship are all provided. For universities with no detected causal relations during lag phase $1-5$, we only present an optimal lag phase based on the Akaike Information Criterion.

it was necessary to conduct unit root and co-integration tests in the number of editorial board members and the number of articles time series for the 20 universities. For this purpose, augmented Dickey-Fuller (ADF) and Johansen co-integration tests were used (Table 1).

The results of Granger causality test showed that for Stanford University, the number of editorial board members was the Granger cause of the number of articles published in lag phases 1-5. For the University of California, Los Angeles (UCLA), the number of editorial board members was the Granger cause of the number of articles published in lag phases 1-3. In contrast, for the University of Strasbourg, the number of articles published was the Granger cause of the number of editorial board members in lag phase 5. However, there was no significant causal relationship in either direction for the other 17 universities.

It is worth noting that although the Granger causality test results suggested unidirectional causality in UCLA, the established regression equations based on the Granger causality test model (eq. (2)) of this university were contradictory with the actual meaning (Table 2). For example, the coefficient of $X_{t-1}$ was significantly nega- tive $(P<0.05)$ in the equation of lag phase 1 as well as the equation of lag phase 2 of UCLA, indicating that when the number of editorial board members from UCLA increased in the previous phase, the number of articles published would decrease in the current phase. This is contradictory to the supposed causal relationship that increase in the number of editorial board numbers would lead to an increase in the scientific output of a university.

Therefore, based on the above results, there was no significant causal relationship between the number of editorial board members and the number of articles published by top 20 universities overall, which is different from our prior hypothesis of causality. However, this does not mean that the number of editorial board members does not affect the number of articles or the number of articles does not affect the number of editorial board members. The results differing from the hypothesis may be due to the following two reasons.

First, the annual changes in the number of editorial board members in the tested universities were not obvious. For example, the minimum number of editorial board members per year from Stanford University was 
Table 2. Regression equation based on Granger causality test model of UCLA

\begin{tabular}{|c|c|}
\hline Lag & Regression equation \\
\hline 1 & $\begin{aligned} Y_{t}= & 80.363+0.413 Y_{t-1}-3.503 X_{t-1} \\
& (\mathbf{0 . 0 0 3}) \quad(\mathbf{0 . 0 4 4}) \quad(\mathbf{0 . 0 2 8})\end{aligned}$ \\
\hline 2 & $\begin{aligned} Y_{t}= & 146.158+0.158 Y_{t-1}-0.077 Y_{t-2}-3.753 X_{t-1}-4.093 X_{t-2} \\
& (\mathbf{0 . 0 0 2}) \quad(0.523) \quad(0.719) \quad(\mathbf{0 . 0 2 1}) \quad(\mathbf{0 . 0 4 3})\end{aligned}$ \\
\hline 3 & 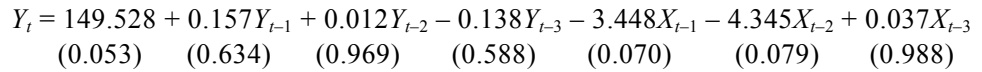 \\
\hline
\end{tabular}

$X$ and $Y$ represent the number of editorial board members and the number of articles published respectively.

Associated $P$ values lower than 5\% are shown in bold.

five, while the maximum number was nine. During the period 1998-2017, the number of editorial board members changed only insignificantly, and it was therefore not easy to show a good corresponding relation with the number of articles published, where there were more obvious changes. As a result, it was not easy to detect the causal relationship between the two variables when the sample size of editorial board members was not large enough.

Second, the causal relationship between the two variables might not be 'rigid'. In other words, an increase or decrease of one variable does not necessarily cause a significant increase or decrease of the other. The universities we had selected were world leaders in chemistry, and increasing or reducing one or two editorial board members in them might have little effect on the number of articles published by these universities. The changes in both the variables could be a result of the combined influences of several factors, such that the number of editorial board members or the number of articles published is only one among several factors.

Research funding, research personnel input and research policy could also be factors that affect the scientific output of a university. Therefore, although the number of editorial board members could be the same, the influence of this variable on the scientific output of universities could differ. From the perspective of factors affecting the selection of board members, although board members are usually excellent scholars with outstanding research ability, there are still other factors influencing their selection. For example, since editorial board members have to review several manuscripts, which might consume time that could be used to conduct scientific research, some excellent scientists might choose not to serve as editorial board members. In addition, geographical factors and reviewer experience are also factors considered in the selection of board members.

\section{Analysis of interviews with editorial board members}

This section summarizes the responses of the editorial board members to our interview questions.

(1) Do editorial board members have an influence on academic discourses?
The academic discourse mentioned here does not refer to academic misconduct, emphasizes preferences and recognition in research topics, paradigms, academic perspectives and evaluation criteria. Most respondents believed that editorial board members had no or only limited influence on academic discourses. The acceptance of an article mainly depends on whether it reports any new discoveries and contributions. However, several respondents pointed out that board members had an influence on the themes or research fields of the articles selected for the journal.

\section{(2) Is there any misuse of editorial power?}

It should be noted that although board members may influence academic discourses, this does not mean that they misuse their own journals to help themselves or their universities publish unworthy articles. Majority of the respondents believed that there was little misuse of power among editorial board members, or that this phenomenon was rare in their journals, which confirms the results of previous studies ${ }^{18-20}$.

(3) Do editorial board members have strong publication and citation records and are the criteria for selecting board members?

Nearly all respondents believed that the editorial board members of their journals had strong publication and citation records. In addition, respondents also mentioned the following factors for selecting board members: academic prestige, research fields, geographical location, experience as a reviewer and contributions to the journal.

(4) Is there a causal relationship between the number of editorial board members and the scientific output of universities?

Most respondents believed that there was no causal relationship between the number of editorial board members and the scientific output of universities, or that there was a non-causal correlation between the two variables. This confirmed the results of the Granger causality test in the present study.

Most respondents did not note a causal relationship between the two variables because they were considering the 
causal relationship from the perspective that editorial board members control the academic discourse. From this perspective, board members' academic discourse might influence a university's scientific output, but to a very limited extent.

However, a strong publication and citation record is one of the most important criteria to select an editorial board member. The greater the quantity and impact of research produced by a university, the more chances that it has a higher number of editorial board members. Similarly, board members could also produce a certain amount of high-impact scientific output for their affiliated university because of their own high research capability. Therefore, we speculate that there may be mutual causality between the number of editorial board members and the scientific output of universities from the perspective that editorial board members have high research capability.

\section{Conclusion}

In this study, we have used time-series data and Granger causality test to explore the causal relationship between the number of editorial board members and the number of articles published by the top 20 universities in the field of chemistry. The Granger causality test results show that the causal relationship between the two variables is not obvious overall. Combining these results with the interviews of some editorial board members and mechanism analysis, we speculate that there may be mutual causality between the two variables from the perspective that editorial board members have high research capability. However, from the perspective that editorial board members control the academic discourse, we consider that such academic discourse might influence the scientific output of a university, but to a limited extent.

There are some limitations to be noted, which also suggest directions for future research. First, since most of the editorial board members reside outside of China and also because of the low response rate of e-mail interviews, our sample size for the interviews was relatively small. Future studies could further expand the sample size of such e-mail interviews. Second, our empirical results are limited to chemistry. The differences between chemistry and other disciplines may restrict the generalization of the findings. Thus, it would be beneficial to conduct similar studies in other disciplines as well.

1. García-Carpintero, E., Granadino, B. and Plaza, L. M., The representation of nationalities on the editorial boards of international journals and the promotion of the scientific output of the same countries. Scientometrics, 2010, 84(3), 799-811.

2. Braun, T. and Dióspatonyi, I., Counting the gatekeepers of international science journals a worthwhile science indicator. Curr. Sci., 2005, 89(9), 1548-1551.

3. Braun, T. and Dióspatonyi, I., The counting of core journal gatekeepers as science indicators really counts. The scientific scope of action and strength of nations. Scientometrics, 2005, 62(3), 297319.

4. Braun, T. and Dióspatonyi, I., Gatekeeping indicators exemplified by the main players in the international gatekeeping orchestration of analytical chemistry journals. J. Am. Soc. Inf. Sci. Technol., 2005, 56(8), 854-860.

5. Zsindely, S., Schubert, A. and Braun, T., Editorial gatekeeping patterns in international science journals. a new science indicator. Scientometrics, 1982, 4(1), 57-68.

6. Chan, K. C. and Fok, R. C. W., Membership on editorial boards and finance department rankings. J. Financ. Res., 2003, 26(3), 405-420.

7. Frey, B. S. and Rost, K., Do rankings reflect research quality? $J$. Appl. Econ., 2010, 13(1), 1-38.

8. Gibbons, J. D. and Fish, M., Rankings of economics faculties and representation on editorial boards of top journals. J. Econ. Educ., 1991, 22(4), 361-366.

9. Kaufman, G. G., Rankings of finance department by faculty representation on editorial boards of professional journal: a note. J. Finance, 1984, 39(4), 1189-1195.

10. Urbancic, F. R., Faculty representation of the editorial boards of leading marketing journals: an update of marketing department. Market. Educ. Rev., 2005, 15(2), 61-69.

11. Wang, X., The relationship between sci editorial board representation and university research output in the field of computer science: a quantile regression approach. Malays. J. Libr. Inform. Sci., 2018, 23(1), 67-84.

12. Braun, T., Dióspatonyi, I., Zádor, E. and Zsindely, S., Journal gatekeepers indicator-based top universities of the world, of Europe and of 29 countries - a pilot study. Scientometrics, 2007, 71(2), 155-178.

13. Burgess, T. F. and Shaw, N. E., Editorial board membership of management and business journals: a social network analysis study of the financial times 40. Br. J. Manage., 2010, 21(3), 627648.

14. Chan, K. C., Fung, H.-G. and Lai, P., Membership of editorial boards and rankings of schools with international business orientation. J. Int. Business Stud., 2005, 36(4), 452-469.

15. Brown, C., The role of web-based information in the scholarly communication of chemists: citation and content analyses of American Chemical Society Journals. J. Am. Soc. Inform. Sci. Technol., 2007, 58(13), 2055-2065.

16. Brogaard, J., Engelberg, J. and Parsons, C. A., Networks and productivity: causal evidence from editor rotations. J. Financ. Econ., 2014, 111(1), 251-270.

17. Yu, L., Study on interactive relationship of different sources of R\&D input and S\&T output based on panel data and panel VAR model. Sci. Res. Manage., 2013, 34(10), 94-102.

18. Bošnjak, L., Puljak, L., Vukojević, K. and Marušić, A., Analysis of a number and type of publications that editors publish in their own journals: case study of scholarly journals in Croatia. Scientometrics, 2010, 86(1), 227-233.

19. Frandsen, T. F. and Nicolaisen, J., Praise the bridge that carries you over: testing the flattery citation hypothesis. J. Am. Soc. Inf. Sci. Technol., 2011, 62(5), 807-818.

20. Sugimoto, C. R. and Cronin, B., Citation gamesmanship: testing for evidence of ego bias in peer review. Scientometrics, 2012, 95(3), 851-862.

ACKNOWLEDGEMENT: This research was supported by MOE (Ministry of Education in China) Project of Humanities and Social Science (Project No. 17YJCZH179).

Received 29 August 2018; revised accepted 23 October 2018

doi: $10.18520 / \mathrm{cs} / \mathrm{v} 116 / \mathrm{i} 1 / 35-39$ 